\title{
Effect of Energy Consumption and Economic Growth towards the environmental quality of Indonesia
}

\author{
Shanty Oktavilia ${ }^{1,2, *}, F X$. Sugiyanto ${ }^{2}$, Firmansyah ${ }^{2}$, Amin Pujiati $^{1}$, Andryan Setyadharma ${ }^{1}$ \\ ${ }^{1}$ Faculty of Economics, Universitas Negeri Semarang, Semarang-Indonesia \\ ${ }^{2}$ Doctoral Program in Economics, Faculty of Economics and Business, Diponegoro University, Semarang-Indonesia
}

\begin{abstract}
Economic development as a process of improving people's welfare in a country can also lead the declining of the environment quality. The degradation of the environment can be caused by the energy consumption required in the development process, as well as pollution. The main purpose of this study is to analyze empirically the impact of energy consumption and economic growth toward environmental quality which is measured by environmental quality index. This study employs the econometric model of panel data of 34 provinces in Indonesia along 2011-2016. The study finds the long-term relationship between energy consumption and economic growth on environmental quality in Indonesia.
\end{abstract}

Keywords : Environmental quality; energy consumption; economic growth; panel data regression

\section{Introduction}

In recent decades, economic growth became the last resort of each country and considered as one and only sustainable development. Traditionally, energy has been considered as the motor of economic progress. However, economic growth can put so much pressure on environment, through energy consumption as transmission line. This gives impact on the contradiction of national economic growth and economic growth policy which was adopted by environment goals. A huge challenge to mediate between economic growth and environmental issue. This becomes interesting and most important on sustainable economic development when ecology and environmental issue is brought to the development debate because it includes welfare of all generations.

One of the governments of Indonesia's effort in terms of reducing environmental annihilation is to reduce greenhouse gas emissions. The effort to reduce greenhouse gas emission corresponds to the target listed on Nationally Determined Contribution (NDC). Emission reducing target on NDC is 29 per cent by 2030 which is 834 million tons worth $\mathrm{CO} 2 \mathrm{e}$ for all sectors. Energy sector itself gets its own reducing portion of 314 million ton $\mathrm{CO} 2 \mathrm{e}$. Greenhouse gas emission on energy sector itself in 2016 was $517.508 \mathrm{Gg}$ CO2e. The biggest contributors of greenhouse gas respectively are energy producer industry $(47,81$ per cent), transportation $(24,71$ per cent), manufacture and construction industry $(14,74$ per cent), fugitive emission of petroleum and natural gas ( 3,73 per cent), others (1,63 per cent), and fugitive emission of solid fuel $(0,43$ per cent). Within the category of energy producer industry, there is a subcategory of power plants as the biggest source of emission (Ministry of Energy and Mineral Resources of the Republic of Indonesia) [1].

It is recognized in general that there is an obvious relation between economic growth and energy consumption. The velocity and capacity of economic development are always boosting the increase energy consumption. There are problems such as unaccommodated and unstructured energy consumption, the dependency on imports, low efficiency and pollution are some inhibitors to sustainable economic growth. Therefore, there is an emerging need to analyze current energy consumption and the effect on economic growth and energy consumption to environmental quality in some countries. The main purpose of this research is to analyse energy consumption to environment quality measured by environment quality index in Indonesia.

\section{Literature Review}

Empirical findings of the causality between energy consumption, $\mathrm{CO} 2$ emissions, and economic growth have shown mixed results in several countries. Some researchers have also carried out further studies on this matter. Research conducted by Baranzini, Weber, Bareit, \& Mathys [2], Ghosh [3], Omri [4] focuses on the relationship between economic growth, energy consumption, and $\mathrm{CO} 2$ emissions with the econometric approach of Granger causality testing, regression models with ordinary models least square (OLS), error correction model (ECM) for long-term and short-term impacts, as well as vector error correction models (VECM).

\footnotetext{
* Corresponding author: oktavilia@mail.unnes.ac.id
} 
Rehman [5] found that the consistency of energy consumption role on environment degradation is the relationship between economic growth, population growth and $\mathrm{CO} 2$ emission showed that the relationship is in the same direction. Population growth impacts on $\mathrm{CO} 2$ emission so that it was significantly influenced environment degradation in developed countries. Economic growth has significant positive impact to $\mathrm{CO} 2$ emission in developed countries.

Oktavilia and Firmansyah [6] found that there was relationship on trade liberalization to environment quality annihilation that was empirically proved by longterm model. The significant impact on trade liberalization to environment quality in Indonesia $n$ longterm showed that there are environment and economic policy that coordinated well to reduce negative impact to environment as an effect to the occurred trade. The hypothesis of Environment Kuznets Curve (EKC) can be proved in Indonesia. Increasing people's income per capita will increase environment degradation. However, after the increasing turning point on economic in Indonesia will reduce environment degradation.

Taghavee [7] found that energy consumption is one of the most unfriendly environmental factors in both the short and long term. Energy consumption produces greenhouse gases and pollutants that increase environmental pollution. In addition, economic growth is another factor that is not environmentally friendly with a significant effect in the long run. Because Iran has a pollutant economy based on fossil fuels, its economic growth leads to environmental pollution.

Ozturk [8] research conducted on 27 developed countries GDP, non-renewable energy consumption, and urbanization increase $\mathrm{CO} 2$ emissions. However, renewable energy consumption, trade openness, and energy prices reduce $\mathrm{CO} 2$ emissions. Increasing fossil fuel consumption will increase pollution as it is known to be a major source of $\mathrm{CO} 2$ emissions. Increased $\mathrm{CO} 2$ emissions are due to increased consumption of fossil fuels which is a non-renewable energy. Urbanization has a positive influence on $\mathrm{CO} 2$ emissions caused by industrial land clearing activities resulting in the opening of employment that leads to social change and the modernization process. The use of renewable energy can reduce $\mathrm{CO} 2$ emissions. In addition, trade openness also reduces emissions due to increased awareness for developed countries about the importance of pollution reduction.

\section{Method}

The analytical model used is a panel data econometric regression model intended to find out the most efficient estimation results because of the increasing number of observations whose implications can increase degrees of freedom. The analysis of this research tested three approaches: Common Effect Model, Fixed Effect Model (FEM) and Random Effect Model (REM) to know the consistency of relationship between each independent variable to dependent variable. The panel was conducted in 34 provinces in Indonesia in the 2011-2016-time frame.

The Common Effect Model or Pooled Least Square (PLS) approach is the simplest panel data model approach because it only combines time series and cross section data. In this model is not considered time and individual dimensions, so it is assumed that the behavior of corporate data is the same in various periods. The fixed effect model (FEM) approach assumes that the regression equation has a constant slope while the intercept varies between individuals. In this case, the intercept of each individual is assumed to have differences due to the special characteristics possessed by each individual. The fixed effect terminology shows that although intercepts vary throughout the individual, each individual intercept does not vary over time, called time invariant. It can also be stated that based on the FEM model, it is assumed that the slope coefficient of the regressor does not vary between individuals and between times. While in REM, the intercept is considered a random variable that has an average value. The intercept is not assumed to be constant, so the Random model is popularly known as the Error Component Model [9].

This study analyzes the influence of economic activity and energy consumption on environmental quality in Indonesia. The environmental quality of the empirical model of this study uses the environmental quality index (EQI) variable. While the gross domestic regional product (GDRB) variable, used as a proxy of economic activity that reflects economic growth. Energy consumption is approximated by the amount of electricity produced (EC). The amount of electricity production is used as a proxy for the amount of energy consumed by society with the assumption that all electricity production is consumed. By including the variables analyzed in this study, the panel data regression equation is:

$E Q I_{i t}=\beta_{0}+\beta_{1} G D R B_{i t}+\beta_{2} E C_{i t}+\varepsilon_{i t}$

\section{Result and Analysis}

The results of analysis using either PLS model, FEM and REM shows the consistency of the relationship of each independent variable to the dependent variable. Nevertheless, in which data panel model can be selected which is most fit used as analysis. By using chow test with Redundant Fixed Effects - Likelihood Ratio shows that $\mathrm{F}$ statistic value 0,2533 with probability $>\alpha 5 \%$. This indicates that statistically the PLS model is more recommended than the FEM model. However, the Hausman test (chi-square statistic 0.686538 , probability $>\alpha 5 \%$ ) indicates that the REM model cannot be rejected so that the REM model is better used than the FEM model [9]. From the test results and consistency of relationships between variables, then the interpretation of the results will be displayed in three data panel approach. 
Table 1. Estimation Results Panel Data Model: Dependent Variable Environmental Quality (EQI)

\begin{tabular}{|c|r|r|r|r|r|r|}
\hline & \multicolumn{2}{|c|}{ PLS } & \multicolumn{2}{c|}{ FEM } & \multicolumn{2}{c|}{ REM } \\
\cline { 2 - 7 } Variable & Coefficient t-Statistic & Coefficient & t-Statistic & Coefficient & t-Statistic \\
\hline LOG(GDRB) & 0.086268 & 3.785538 & 0.086250 & 3.741323 & 0.086268 & 3.750480 \\
\hline LOG(EC) & -0.165153 & -8.597237 & -0.165351 & -8.492328 & -0.165153 & -8.517618 \\
\hline C & 4.394871 & 31.74271 & 4.396570 & 31.43931 & 4.394871 & 31.44874 \\
\hline$R^{2}$ & \multicolumn{2}{|c|}{0,603946} & \multicolumn{2}{|c|}{0,606466} & 0,603942 \\
\hline
\end{tabular}

Notes: all variable significant at $\alpha 1 \%$

In the estimation results in table 1 shows that in the three approaches, economic growth variables are positively related to environmental quality, while energy consumption variables are negatively related to environmental quality. The influence of the two independent variables on the environmental quality variable was significant at 99 percent ( $\alpha 1$ percent) degree of trust in the three data panel approaches used. The value of $R_{2}$ in the three approaches in the empirical model averages about 0.60 , which means that 60 percent of the independent variables in the model are able to explain the variation of the dependent variable, while the other 40 percent are explained by the variables outside the empirical model.

The estimation results using the PLS data panel show that the average intercept value for the overall model is 4.3948 (significant at alpha 1 percent). This means that the PLS data panel is able to explain the differences in variable behavior of economic growth and energy consumption in 34 provinces on the dependent variable. Economic growth variable has positive and significant effect with coefficient of 0,0862 which means increase of economic growth by 1 percent will improve environmental quality in Indonesia equal to 0,08 percent. $\mathrm{EC}$ is negatively related and significant to EQI. The EC coefficient value of -0.1651 shows an increase in energy consumption by 1 percent will decrease the environmental quality by 0.16 percent.

The estimation result using FEM data panel shows that the average intercept value for the whole model is 4.3965 (significant at alpha 1 percent), which means the data panel with FEM is able to explain the difference of independent variable behavior on the empirical model to the dependent variable. Economic growth variable has positive and significant effect with coefficient of 0,0862 which means increase of economic growth by 1 percent will increase environmental quality in Indonesia equal to 0,086 percent. EC is negatively related and significant to EQI. The EC coefficient value of -0.1653 shows an increase in energy consumption by 1 percent will decrease the environmental quality by 0.165 percent.

Estimates with the REM approach do not show many different results. The average intercept value for the whole model is 4.3948 (significant at alpha 1 percent), which means the data panel with REM is able to explain the difference of independent variable behavior on the empirical model to the dependent variable. The independent variable relation also shows consistent result that is economic growth variable has positive and significant influence with coefficient 0,0862 . This means an increase in economic growth by 1 percent will improve the environmental quality in
Indonesia by 0.086 percent. Meanwhile, energy consumption is negatively related to environmental quality. The EC coefficient value of -0.1651 shows an increase in energy consumption by 1 percent will decrease the environmental quality by 0.1651 percent.

The results of the analysis with the three data panel approaches show that development in Indonesia that drives economic growth affects the environmental quality positively. This means that development aspects have taken into consideration the concept of sustainable development that considers the components of environmental quality. This study also proves a negative and significant relationship between the use of energy and environmental quality in Indonesia.

Using inverse variables from $\mathrm{CO}_{2}$ emissions, namely EQI, this study reinforces the findings of Jafari, Othman, and Nor [10] and Bloch, Rafiq, and Salim [11]. The conclusion of their study states that energy consumption is positively related to $\mathrm{CO} 2$ emissions. This means that in Indonesia, increased consumption increases emissions in $\mathrm{CO} 2$. While in this study the increase in energy consumption in reducing environmental quality.

\section{Conclusion}

As the economy progresses and develops, development is followed by ecological problems. There is a tradeoff, especially in developing and poor countries, that development in addition to the effect on economic growth will cause environmental damage. This is due to the development process that is still concentrated in the primary sector, the industrialization with the energy needs of potentially high pollutants, while the technology used is also not environmentally friendly. The results of this study empirically prove that the more advanced and developed a country, awareness the importance of better environmental quality. Economic growth will be followed by improved environmental quality. However, the use of energy both by industry and household empirically still negatively affect the environment. The higher awareness of the importance of energy and the effects it has on the environment, there needs to be support for energy saving, new energyefficient and environmentally friendly energy replacement and the use of new technologies that are energy-efficient and environmentally friendly.

This study has some limitations of data so that not all provinces can be accommodated. In addition, this study uses aggregate variables, so it is not able to show the relationship behavior with more detail. Further research can be expanded and enriched using more complex environmental indicators and details that represent some environmental components.

\section{References}

1. Ministry of Energy and Mineral Resources. Kajian Emisi Gas Rumah kaca 2017, https://www.esdm.go.id/assets/media/content/conte nt-kajian-emisi-gas-rumah-kaca-2017.pdf. (2017). 
2. A. Baranzini, S. Weber, M. Bareit, and N. A. Mathys, The causal relationship between energy use and economic growth in Switzerland. Energy Economics, 36, 446-470 (2013).

3. A. Omri, CO2 emissions, energy consumption and economic growth nexus in MENA countries: Evidence from simultaneous equations models, Energy Economics, 40, 657-664 (2013).

4. M. M. Rehman, \& M. Rashid, Energy consumption to environmental degradation, the growth appetite in SAARC nations, Renewable Energy, 111, 284294, (2017).

5. S. Ghosh, Examining carbon emissions-economic growth nexus for India: A multivariate cointegration approach, Energy Policy, 38, 26133130 (2010).

6. S. Oktavilia \& Firmansyah, The Relationships of Environmental Degradation and Trade Openness in Indonesia, International Journal of Economics and Financial Issues, 6(S6) (2016).

7. V. M. Taghavee, Aloo, A.S. \& Shirazi, J. K. Energy, Environment, and Economy Interactions in Iran with Cointegrated and ECM Simultaneous Model, Procedia Economics and Finance, 36, 414 424 (2016).

8. I. Ozturk \& U. Al-Mulali, The investigation of environmental Kuznets curve hypothesis in the advanced economies: The role of energy prices, Renewable and Sustainable Energy Reviews, 54, 1622-1631 (2016).

9. Gujarati DN and Porter DC, Basic Econometrics 5th ed. New York: McGraw-Hill (2009)

10. Y. Jafari, J. Othman, \& A. H. S. M. Nor, Energy consumption, economic growth and environmental pollutants in Indonesia, Journal of Policy Modeling, 34, 879-889 (2012).

11. H. Bloch, S. Rafiq, \& R. Salim, Coal consumption, CO2 emission and economic growth in China: Empirical evidence and policy responses, Energy Economics, 34, 518-528 (2012). 